\title{
The Influence of Hope on the Relationship Between Racial Discrimination and Depressive Symptoms
}

\author{
Kira Hudson Banks, Jennifer L. Singleton, \\ and Laura P. Kohn-Wood
}

This study investigated how hope influences the relationship between discrimination and depressive symptoms. Results from participants' $(N=318)$ responses suggest that increased levels of hope were directly related to decreased levels of depressive symptoms. However, increased levels of hope were also related to a stronger relationship between discrimination and depressive symptoms.

\begin{abstract}
Este estudio investigó cómo la esperanza influye en la relación entre discriminación y síntomas depresivos. Los resultados obtenidos a partir de las respuestas de los participantes $(N=318)$ sugieren que unos niveles más elevados de esperanza estuvieron directamente relacionados con unos niveles más bajos de síntomas depresivos. Sin embargo, los niveles superiores de esperanza también estuvieron relacionados con una relación más fuerte entre discriminación y síntomas depresivos.
\end{abstract}

W ithin the past 2 decades, research on the effects of discrimination on mental health has increased. These studies have indicated that increased exposure to discrimination is related to increased reporting of psychiatric problems, in particular, depressive symptoms (Banks \& KohnWood, 2007; Banks, Kohn-Wood, Spencer, 2006; Kessler, Mickelson, \& Williams, 1999). The field has progressed from assessing the frequency of experiences of discrimination across racial and ethnic populations to understanding cognitive variables that might influence the experience and outcomes associated with discriminatory events. Counseling psychologists have called for research investigating variables that affect the experience of discrimination with the hope that this understanding can inform and guide work with targeted populations (Barnes \& Lightsey, 2005; Fischer \& Shaw, 1999). The goal of the present study was to build on the current theoretical and empirical knowledge regarding the association of discrimination and depressive symptoms and to investigate how hope may influence this relationship in African American students. In addition, as the diversity of college students who use counseling services increases (Davidson, Yakushka, \& Sanford-Martens, 2004), it is important to consider within-group experiences that might inform work with diverse populations.

\section{racial discrimination}

Racial discrimination, or differential treatment of individuals on the basis of race, has changed over time and is now less overt (e.g., being ignored/

Kira Hudson Banks, Department of Psychology, Illinois Wesleyan University; Jennifer L. Singleton, Southwestern Indiana Mental Health Center, Evansville, Indiana; Laura P. Kohn-Wood, Department of Psychology, University of Michigan. Correspondence concerning this article should be addressed to Kira Hudson Banks, Department of Psychology, Illinois Wesleyan University, PO Box 2900, Bloomington, IL $61702-2900$ (e-mail: kbanks@iwu.edu).

(C) 2008 American Counseling Association. All rights reserved. 
overlooked while waiting in line, being mistaken for someone who serves others) than earlier forms of discrimination (e.g., lynching, being denied service at a restaurant; Harrell, 2000). However, even less severe incidents may be stressful, leading to feelings of resignation and hopelessness (Deitch et al., 2003; Harrell, 2000). Chronically stressful or discriminatory events can accumulate over time, resulting in decreased levels of mental health (Deitch et al., 2003; McGonagle \& Kessler, 1990). In particular, this study examines racial discrimination experienced in the context of everyday experiences (e.g., being ignored, overlooked, or not given service; Harrell, 2000).

Although discrimination is a negative experience that is common to many groups in the United States, African Americans are more likely to report experiencing racial discrimination than are other racial and ethnic groups (Kessler et al., 1999). In one study, researchers found that $44.4 \%$ of non-Hispanic Whites, as compared with only $8.8 \%$ of non-Hispanic Blacks, reported that they had never experienced a daily discriminatory event (Kessler et al., 1999). A recent survey found that over $75 \%$ of college students (i.e., African American, White, Hispanic, and Asian American students) agreed that "racial hostility is still felt although not openly expressed" (Biasco, Goodwin, \& Vitale, 2001, p. 527). The experience of discrimination continues to be prevalent in the lives of African Americans.

Although research has indicated a consistent link between discrimination and decreased levels of mental health, not everyone who experiences discrimination has decreased mental health. Therefore, researchers have examined variables that influence this relationship (e.g., coping, self-esteem, racial identity; Banks \& Kohn-Wood, 2007; Barnes \& Lightsey, 2005; Fischer \& Shaw, 1999; Sellers \& Shelton, 2003). Individuals for whom race was central (Sellers \& Shelton, 2003), who focused on issues of race (Banks \& Kohn-Wood, 2007), and who had low levels of self-esteem (Fischer \& Shaw, 1999) were found to report lower levels of distress related to discrimination, whereas coping was not found to affect the relationship (Barnes \& Lightsey, 2005). It is important to understand how other cognitive variables, such as hope, might influence the relationship between discrimination and mental health.

\section{hope}

Hope is the perceived ability to meet one's goals, and this perception has two components: agency (i.e., a sense that one can complete goals) and pathways thinking (i.e., a belief in one's ability to develop multiple ways to meet goals; Snyder, 1995). For instance, if an individual has a goal to attend college, higher levels of agency would indicate a belief in the ability to go to college, and higher levels of pathways thinking would indicate the ability to see multiple ways to actually attend college. This cognitive set is conceptualized as influencing numerous variables.

Hope has been found to positively correlate with optimism (Huprich \& Frisch, 2004), self-efficacy (Snyder et al., 1991), and academic achievement in college students (Shorey, Snyder, Yang, \& Lewin, 2003). Hope is negatively correlated with depressive symptoms (Huprich \& Frisch, 2004; Snyder et al., 
1991). Overall, high hope is associated with better adjustment, as compared with low hope. The present study examined whether hope influenced the relationship between discrimination and depressive symptoms.

Several studies have empirically examined the influence of hope on the experience of depressive symptoms. Kwon (2000) found that high hope and more mature defense mechanisms (i.e., intellectualization and humor) were more adaptive than high hope and less mature defenses (e.g., turning against self). In a follow-up study, higher levels of depressive symptoms were found with the combination of high hope and high defense immaturity compared with high hope and low defense immaturity (Kwon, 2002). These findings provide evidence that high hope is not simply associated with lower levels of depressive symptoms.

Given recent research, which calls into question the direct association between high levels of hope and better adjustment, it is important to examine how hope serves individuals who are targets of racial discrimination. Theoretical conceptualizations have cautioned that racial discrimination could lead to decreased hope for people of color (Snyder, 1995), or these groups could experience false hope, which occurs when an individual's high hope is incongruent with the circumstances (Snyder, 2002). However, research that has empirically examined hope in populations of color has been limited. In research examining components of hope across groups in a college sample (Chang \& Banks, 2007), college students who self-identified as Latino were found to have significantly higher levels of agency compared with European American and African American college students. In addition, African American and Latino college students reported significantly higher levels of pathways thinking when compared with European American and Asian American college students. It is possible that these students had a high self-perception of agency and pathways thinking because they had experienced the success of enrolling in college. However, it would be important to extend this research by examining the possible benefits or limitations of high and low levels of hope within this population. In addition, given the varied pattern of agency and pathways thinking found across groups, it is also important to examine both overall hope and the separate components of agency and pathway to understand the possibility of differing relationships.

In another study that examined hope within a sample of African American college students, the finding was that hope influenced the relationship between coping and life satisfaction (Danoff-Burg, Prelow, \& Swenson, 2004). African American students with higher levels of hope reported greater life satisfaction and less frequent use of active coping with discrimination compared with students having lower levels of hope, who reported greater life satisfaction associated with more frequent use of active coping with discrimination. The authors suggested that individuals with lower levels of hope were more likely to use coping strategies that enlisted social support, thereby increasing life satisfaction. It is also possible that the lower levels of coping with discrimination, which were found in individuals with higher levels of hope, were associated with a lack of awareness of discrimination; therefore, higher hope paired with 
lack of awareness might have exacerbated the experience of discrimination, thereby decreasing reported life satisfaction.

Dynamics in the United States continue to shift in relation to discrimination. However, for African American students at predominantly White institutions, the circumstances have not changed as dramatically. Despite previous successes, which have fostered high levels of hope, African American students might find these self-perceptions countered by the larger campus community (e.g., roommates, staff, faculty). Therefore, the effects of racial discrimination on mental health might be exacerbated for individuals with high hopes who have confidence in their abilities within a discriminatory environment. Although at first glance this suggestion might seem paradoxical, the results of research on the effects of self-esteem on the relationship between discrimination and mental health among African American college students supports the notion (Fischer \& Shaw, 1999). In the study, Fischer and Shaw examined numerous variables that might influence the relationship, and they hypothesized that self-esteem would "protect" students from the deleterious effects of discrimination. Instead, they found that individuals with high self-esteem reported decreased levels of mental health in relation to discrimination as compared with individuals who had low self-esteem.

\section{current study}

Recent research has indicated that conceptualizing discrimination within a stress and coping framework allows for a more complex understanding of how situational and person factors contribute to an experience (Clark, Anderson, Clark, \& Williams 1999; Harrell, 2000; Sellers \& Shelton, 2003). It has generally been assumed that high hope facilitates adjustment. However, recent research provides evidence showing that high hope is not always correlated with positive outcomes (Danoff-Burg et al., 2004; Kwon, 2002). Given the pervasive and insidious nature of discrimination, it is important to investigate how the relationship between racial discrimination and depressive symptoms might be influenced by hope. We hypothesized that (a) increased levels of hope would be associated with lower levels of depressive symptoms; and (b) hope would influence the relationship between discrimination and depressive symptoms, specifically, that individuals with higher levels of hope would have a stronger positive relationship between the racial discrimination and depressive symptoms when compared with individuals reporting lower levels of hope.

\section{method}

\section{PARTICIPANTS}

African American, U.S.-born students $(N=318)$ from two midwestern state universities were recruited to participate in this study. African American students made up $12 \%$ of the student population at one university and $7 \%$ at the other. Women con- 
stituted $65 \%$ of the study participants, and the average age was 20 years. Sixty-eight percent of the sample were in-state students, and $56 \%$ reported being employed. The participants included freshman (20\%), sophomores (31\%), juniors (26\%), seniors $(19 \%)$, and some students beyond their 4th year. Mother's education was used as a proxy for socioeconomic status, and the most commonly reported levels of mother's education were "some college" (33\%) and "college diploma" (39\%).

\section{PROCEDURE}

Participants were recruited at two institutions. One group was recruited through flier advertisements, direct contact, and by word-of-mouth, and the other group was drawn from the subject pool of introductory psychology students. Students who chose to participate in the study signed consent forms. Because there was a possibility that the nature of the questions posed in the study might trigger in students depressive symptoms or difficult memories about troublesome events, they were given information about the counseling center at their university. At one institution, students were debriefed and given course credit for completing the study. At the other, students were debriefed and given $\$ 10$ for their participation.

\section{MEASURES}

Hope. Hope was measured using a multidimensional scale, the Hope Scale, that assesses two components, agency and pathways thinking, and overall hope (Snyder et al., 1991). Four items address the agency component (e.g., "I meet the goals that I set for myself"; current sample $\alpha=.75$ ), and four items address the pathways thinking component (e.g., "I can think of many ways to get out of a jam"; current sample $\alpha=.67$. Respondents rate items using a 4-point Likerttype scale $(1=$ definitely false, $4=$ definitely true $)$; higher scores indicate stronger belief in the ability to succeed in achieving or navigating multiple paths to a goal. Higher overall scores, a summation of the scores for the items for the entire Hope Scale, indicate a greater level of overall hope $(\alpha=.80)$.

Daily life experiences. Racial discrimination was measured by the Daily Life Experience subscale from the Racism and Life Experience Scales developed by Harrell (1997). This subscale is a self-report measure of the frequency of 18 everyday discrimination events (e.g., "being treated rudely or disrespectfully" and "others expecting your work to be inferior"; current sample $\alpha=.94$ ). (Participants were asked how often they had experienced each type of racial discrimination incident using a 6-point Likert-type scale, with higher scores indicating more experiences of discrimination.)

The Center for Epidemiological Studies Depression Scale (CES-D). The CES-D, a 20-item measure, assesses the presence and intensity of depressive symptoms (Radloff, 1977; current sample $\alpha=.89$ ). (Participants were asked to rate the frequency for each symptom during the "past week" [e.g., "I felt fearful," or "I felt that people disliked me."]). Responses range from 1 (rarely or none of the time-less than 1 day) to 4 (most of the time - 5 to 7 days). Scores are summed with higher scores indicating more depressive symptoms. This scale has been used frequently in previous research with African Americans (Barbee, 1992). 
Demographics. Gender, mother's education, location, and age were used as control variables in the regression analysis. It was conceptualized that these variables might influence hope and should be accounted for in the model. Given the minimal research on hope within populations of color, it is unclear if mother's level of educational attainment might positively influence participants' own levels of hope or provide access to opportunities that could have similar effects. In previous research, African American women whose mothers had college experience reported fewer depressive symptoms compared with their first-generation college peers (Reed, McLeod, Randall, \& Walker, 1996). In addition, older participants' higher numbers of interactions with systems and institutions might be related to the development of hope. Parental education was measured categorically and was defined as "some high school," "high school diploma," "some college," and "college diploma." Mother's education was used rather than father's education because of missing data for fathers. Age was measured continuously in years.

\section{results}

We conducted $t$ tests to compare students who were recruited at the two sites on all study variables. Results indicated that students recruited at the larger state institution were younger $(t=-2.26, p \leq .05)$; their mothers had a higher level of education $(t=7.52, p \leq .001)$; and they had higher levels of hope $(t=2.75, p \leq .01)$, agency $(t=2.87, p \leq .01)$, pathways thinking $(t=1.99, p \leq .05)$, and experiences with racial discrimination $(t=4.28, p \leq .001)$ than did students at the smaller state institution. Given these findings, type of location was included as a control variable in subsequent regression analyses. A significant gender difference was also indicated by $t$ tests in that men reported significantly more experiences with racial discrimination as compared with women $(t=-2.49, p \leq .05)$. Therefore, gender was also included as a control variable in subsequent analyses. Descriptive analyses were conducted, and means and standard deviations along with bivariate correlations of sample variables are presented in Table 1. Overall scores for

\section{TABLE 1}

\section{Means, Standard Deviations, and Pearson Correlations for Study Variables}

\begin{tabular}{|c|c|c|c|c|c|c|c|c|c|c|}
\hline Variable & $M$ & $S D$ & 1 & 2 & 3 & 4 & 5 & 6 & 7 & 8 \\
\hline 1. Age & 20.20 & 2.36 & - & & & & & & & \\
\hline 2. Mother's education & 2.04 & 0.94 & $-.17^{\star \star}$ & - & & & & & & \\
\hline 3. Gender & & & .10 & .05 & - & & & & & \\
\hline 4. Hope & 51.40 & 7.76 & .07 & .08 & .06 & - & & & & \\
\hline 5. Agency & 26.42 & 4.25 & .03 & .08 & .01 & $.88^{\star *}$ & - & & & \\
\hline $\begin{array}{l}\text { 6. Pathways thinking } \\
\text { 7. Racial }\end{array}$ & 24.98 & 4.50 & .10 & .06 & .10 & $.89^{* *}$ & $.57^{* *}$ & - & & \\
\hline $\begin{array}{l}\text { discrimination } \\
\text { 8. Depressive }\end{array}$ & 33.86 & 18.34 & -.06 & $.14^{*}$ & $.14^{*}$ & -.07 & -.09 & -.05 & - & \\
\hline symptoms & 13.96 & 9.53 & .02 & .04 & -.03 & $-.35^{\star *}$ & $-.33^{* *}$ & $-.29^{* *}$ & $.28^{* *}$ & - \\
\hline
\end{tabular}

${ }^{*} p \leq .05 .{ }^{* *} p \leq .01$. 
depressive symptoms were below the cutoff for clinical significance (Radloff, 1977), and no significant gender differences emerged.

Hierarchical multiple regression analyses were conducted to examine the association of the study variables with depressive symptoms. Variables were centered to minimize multicollinearity (Cohen \& Cohen, 1983). In Model 1, to test Hypothesis 1, all study variables were entered simultaneously into Step 1. Subsequently, to test Hypothesis 2, the interaction between overall hope (the total score for the full Hope Scale) and racial discrimination was added to Step 2. The second model differed in that the interactions between the two components of hope (agency and pathways thinking) and racial discrimination were added to Step 2 because these variables are conceptualized as distinct components. However, it is to be noted that the correlation between agency and pathways thinking was .57 ( $p \leq .01)$, which might suggest some multicollinearity, although theoretically these two variables have been considered distinct.

In Model 1, Step 1 of the hierarchical analysis explained $18 \%$ of the variance in depressive symptoms, $F(6,311)=12.74, p \leq .001$ (see Table 2$)$. In this step, significant effects were found for hope $(\beta=-.33, p \leq .001)$ and racial discrimination $(\beta=.27, p \leq .001)$. Regarding hope, individuals who reported high levels of overall hope were less likely to endorse depressive symptoms. Individuals who reported high levels of racial discrimination were more likely to endorse depressive symptoms.

In Step 2, $F(1,310)=6.40, p \leq .001$, the interaction between hope and racial discrimination was entered, resulting in a significant increase in the overall variance $\left(\Delta R^{2}=.02\right)$. The model explained $20 \%$ of the variance of depressive symptoms. Despite a significant increase in variance explained, the small amount of increase in understanding depressive symptoms should be noted. In this step, significant coefficients emerged for hope $(\beta=-.36, p \leq .001)$ and racial discrimination $(\beta=.24, p \leq .001)$ and for the interaction between hope and racial discrimination $(\beta=.13, p \leq .05)$. The pattern of relationship for hope and racial discrimination remained similar to that of Step 1. The find-

\section{TABLE 2}

\section{Hierarchical Regression Analyses Predicting Depressive Symptoms, Examining the Interaction of Racial Discrimination and Hope}

\begin{tabular}{|c|c|c|c|c|c|}
\hline Step and Variable & $B$ & SE B & $\beta$ & $R^{2}$ & $\Delta \boldsymbol{R}^{2}$ \\
\hline Step 1 & & & & $.18^{\star * *}$ & \\
\hline Location & 0.82 & 1.10 & .04 & & \\
\hline Age & 0.30 & 0.21 & .08 & & \\
\hline Mother's education & 0.71 & 0.57 & .07 & & \\
\hline Gender & -1.05 & 1.03 & -.05 & & \\
\hline Hope & -0.41 & 0.06 & $-.33^{\star \star \star}$ & & \\
\hline Racial discrimination & 0.14 & 0.03 & $.27^{\star \star \star}$ & & \\
\hline Step 2 & & & & $.20^{\star \star * *}$ & $.02^{\star \star}$ \\
\hline Racial Discrimination $\times$ & & & & & \\
\hline Hope & 0.01 & 0.00 & $.17^{* *}$ & & \\
\hline
\end{tabular}

Note. Location $=$ large and small state universities where participants were recruited for this study. ${ }^{* *} p \leq .01 .{ }^{* * *} p \leq .001$. 
ing for the interaction suggests that participants who scored higher on hope had a stronger positive association between increased racial discrimination and depressive symptoms as compared with those participants who had lower levels of hope (see Figure 1).

In Model 2, Step 1 of the hierarchical analysis explained 18\% of the variance, $F(7,310)=10.99, p \leq .001$ (see Table 3 ). In this step, significant effects were found for agency $(\beta=-.23, p \leq .001)$, pathways $(\beta=-.15, p \leq .05)$, and racial discrimination $(\beta=.26, p \leq .001)$. This finding indicates that individuals who reported high levels of agency and pathways thinking were less likely to endorse depressive symptoms, whereas those individuals reporting high levels of racial discrimination were more likely to endorse depressive symptoms.

In Step 2, the interaction between the two components of hope (agency and pathways thinking) and racial discrimination was entered, resulting in a significant increase in the overall variance $\left(\Delta R^{2}=.02\right)$. Despite a significant increase in variance explained, the small amount of increase should be noted. The model explained $20 \%$ of the variance of depressive symptoms, $F(1,308)=3.83$, $p \leq .001$. In this step, significant coefficients emerged for agency $(\beta=-.26, p \leq .001)$, for pathways thinking ( $\beta=-.15, p \leq .05)$, for racial discrimination $(\beta=.25, p \leq .001)$, and for the interaction between pathways thinking and racial discrimination $(\beta$ $=.13, p \leq .05)$. The interaction between agency and racial discrimination was not significant. The pattern of relationships for agency, pathways thinking, and racial discrimination remained similar to that of Step 1. The finding for the interaction indicates that those who scored higher on pathways had a stronger positive association between increased racial discrimination and depressive symptoms as compared with participants who had lower levels of pathways thinking. The pattern of results is similar to the pattern shown in Figure 1.

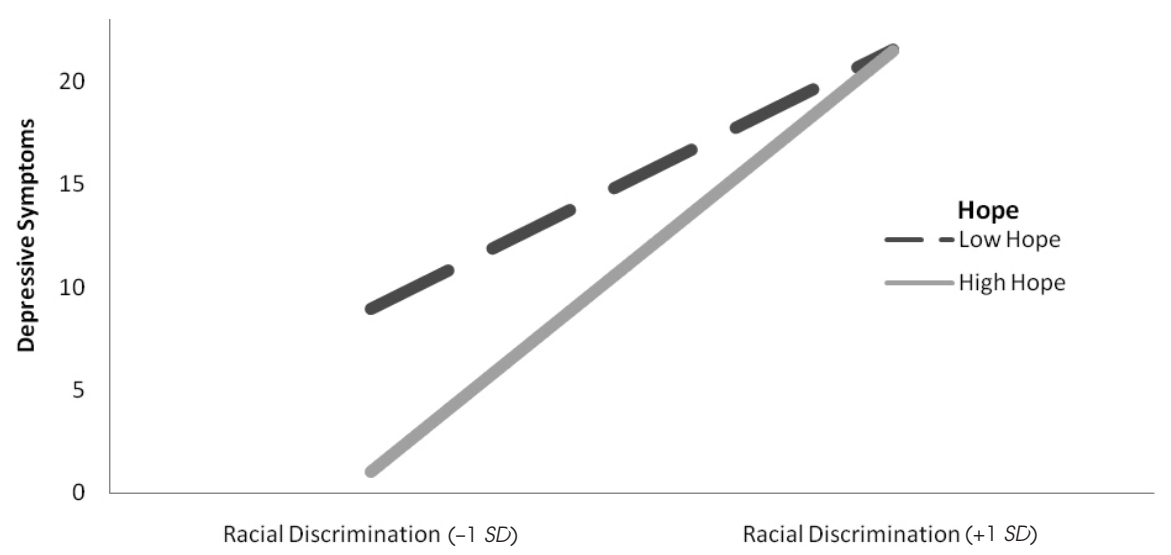

FIGURE 1

The Interaction of Hope and Racial Discrimination

Note. Racial Discrimination and Depressive Symptoms are summed scores. Racial discrimination is graphed at $+/-1 S D$. Hope was grouped as follows: scores below the mean = low hope and scores above the mean = high hope. 
TABLE 3

Hierarchical Regression Analyses Predicting Depressive Symptoms, Examining the Interaction of Racial Discrimination, Agency, and Pathways Thinking

\begin{tabular}{|c|c|c|c|c|c|}
\hline Step and Variable & $B$ & SE B & $\beta$ & $R^{2}$ & $\Delta \boldsymbol{R}^{2}$ \\
\hline Step 1 & & & & $.18^{\star \star \star}$ & \\
\hline Location & 0.77 & 1.10 & .04 & & \\
\hline Age & 0.29 & 0.21 & .07 & & \\
\hline Mother's education & 0.72 & 0.57 & .07 & & \\
\hline Gender & -1.13 & 1.04 & -.06 & & \\
\hline Agency & -0.51 & 0.14 & $-.23^{\star \star *}$ & & \\
\hline Pathways thinking & -0.32 & 0.13 & $-.15^{\star}$ & & \\
\hline Racial discrimination & 0.14 & 0.03 & $.26^{\star \star \star}$ & & \\
\hline Step 2 & 5.95 & 4.99 & & $.20^{\star * \star}$ & $.02^{\star *}$ \\
\hline Racial Discrimination $\times$ & & & & & \\
\hline Agency & 0.01 & 0.01 & .06 & & \\
\hline Racial Discrimination $\times$ & & & & & \\
\hline Pathways Thinking & 0.01 & 0.01 & $.14^{*}$ & & \\
\hline
\end{tabular}

Note. Location = large and small state universities where participants were recruited for this study. ${ }^{*} p \leq .05 .{ }^{* *} p \leq .01 .{ }^{* * *} p \leq .001$.

\section{discussion}

That the experience of racial discrimination is a part of the college experience for many African American students is supported by previous research (Banks \& Kohn-Wood, 2007; Biasco et al., 2001; Sellers \& Shelton, 2003). Also consistent with previous research, male students in the current study reported experiencing significantly more encounters with racial discrimination than did female students (Banks \& Kohn-Wood, 2007; Sellers \& Shelton, 2003). Reported levels of hope, agency, and pathways thinking for the current study were also similar to those of previous studies with an African American sample (Danoff-Burg et al., 2004).

Regarding depressive symptomatology, the symptoms reported for the current sample are comparable to those indicated in previous studies investigating depressive symptoms in African American college students (Sellers \& Shelton, 2003). The lack of gender differences in depressive symptoms for the current study is also consistent with previous data on college-aged students (Sellers \& Shelton, 2003), yet inconsistent with previous studies that have indicated an overrepresentation of women who have received a diagnosis of depression (U.S. Department of Health and Human Services, 2001).

For Model 1 (overall hope) Hypothesis 1, increased levels of overall hope were associated with decreased depressive symptoms. This finding supports the hypothesis and is consistent with previous research (Huprich \& Frisch, 2004; Snyder et al., 1991). Also in the current study, greater perceived ability to meet a goal was related to lower levels of depressive symptoms compared with the levels of depressive symptoms for individuals who do not endorse this belief as strongly. Also similar to previous research is the finding that increased experience of racial discrimination is associated with increased depressive 
symptoms (Kessler et al., 1999). Hypothesis 2 was also supported given that the interaction between overall hope and depressive symptoms indicates that individuals with high hope reported experiencing more depressive symptoms when reporting discrimination compared with individuals with low hope. This finding parallels previous results showing that self-esteem influenced the relationship between discrimination and mental health in that high selfesteem was associated with greater distress compared with low self-esteem (Fischer \& Shaw, 1999). It is important to keep in mind that, in the current study, the relationship between discrimination and depressive symptoms was also positive for individuals with low hope. However, that same relationship was significantly stronger for students with high hope.

Model 2 also supported the first hypothesis because both of the components of hope were found to negatively correlate with depressive symptoms. The sense that a goal can be completed (agency) and the ability to navigate multiple ways (pathways thinking) to achieve that goal were related to lower levels of depressive symptoms compared with levels of depressive symptoms for individuals who did not endorse those beliefs as strongly. Regarding Hypothesis 2, pathways thinking alone emerged as having significant interaction with racial discrimination and depressive symptoms. Individuals who reported high pathways thinking had a stronger positive relationship between discrimination and depressive symptoms compared with those with low pathways thinking. No interaction was found between agency and discrimination.

These results are similar to results for previous research that found that high levels of variables perceived as adaptive were not consistently so (Danoff-Burg et al., 2004; Reed et al., 1996). One study found that individuals with high hope were more likely to exhibit low levels of coping with discrimination compared with individuals with low hope who exhibited high levels of coping (Danoff-Burg et al., 2004). Another study found lower levels of distress for individuals with low self-esteem when compared with individuals who had high-self esteem (Fischer \& Shaw, 1999). Although it might sound good to promote high levels of hope and self-esteem for all, these variables might not be as protective in relation to the experience of discrimination as many might believe them to be.

The current study found that when hope was examined as an overarching construct, its interaction with discrimination indicated that individuals with high hope reported higher levels of depressive symptoms than did individuals with low hope. Furthermore, when the two components of hope were examined separately to see if their interaction with discrimination varied, only pathways thinking emerged as significant. The group with high levels of pathways thinking showed a stronger relationship between experiences of increased racial discrimination and increased depressive symptoms when compared with individuals with low pathways thinking. These findings indicate that the nature of the influence of hope is not what might be intuitively expected. One might make the assumption that hope and its components act as buffers given the direct relationship between hope and decreased depressive symptoms. 
It is interesting to note that when the components of hope were separated, this pattern of findings did not emerge for agency. The nature of pathways thinking is that an individual feels capable of constructing various ways to achieve a set goal. Perhaps the obstacle of discrimination is more detrimental to mental health in individuals who believe they are adept at navigating the way to success as compared with those who do not hold that belief as strongly. It is possible that ability to develop multiple paths to a goal, in Model 2, is what is driving the significant interaction found for overall hope in Model 1. Perhaps it is this particular component of hope that influences the experiences of depressive symptoms in relation to discrimination.

Research has shown that individuals who have an understanding of discrimination fare better when faced with discrimination as compared with those who lack such awareness or understanding (Crocker \& Major, 1989; Sellers \& Shelton, 2003). Translated to the current study, such findings might be interpreted to mean that those who report higher levels of pathways thinking have lower levels of awareness of the obstacles of discrimination. Perhaps those with higher levels of hope and pathways thinking have a sense of being immune to such discrimination experiences based on a track record of success. Therefore, when they experience discrimination, there might be a stronger correlation with decreased mental health for them as compared with those who do not have similarly high levels of pathways thinking and overall hope. At first glance it seems paradoxical, but the findings seem to suggest that the experience of discrimination for individuals with low hope and, specifically, low pathways thinking might be less incongruent with expectations; therefore, these groups of people experience less distress. More data are needed to further clarify these relationships.

These findings serve as empirical support for Snyder's (2002) theoretical consideration that in some instances, higher levels of hope can be maladaptive. It is possible that individuals with higher levels of hope and pathways thinking are able to continue toward their goals. However, the experience of discrimination-one that is related to internal yet uncontrollable traits - seems to dash hopes. For example, an African American college student who has high hopes may be able to find many ways of meeting goals and may seem intent on reaching them. The high levels of hope and pathways thinking are related to lower levels of depressive symptoms. Unfortunately, the findings of the current study and those of other research (Danoff-Burg et al., 2004) indicate that when this individual experiences discrimination, high levels of hope are no longer protective. Having to study harder, longer, or in a different way are all factors an individual can work to address, but racial discrimination is not something that can be controlled. Discrimination is an unfortunate reality that cannot be avoided by working harder.

Some might argue that having high hopes in certain situations is a "false hope," and individuals should not hold onto it in the face of real adversity. However, in the current study, it is discrimination that is the limiting factor, 
not the ability of the student. Given the example of the African American student just outlined in the preceding paragraph, the goal of success is congruent with the student's ability. Discrimination is the barrier that limits the student. It is not that the student has inaccurate expectations; therefore, it would be incorrect to label hopeful expectations as "false."

It is important not to interpret these findings as a deterrent to fostering hope in clients because hope is correlated with numerous positive adjustment variables. It is, however, necessary to be aware that the relationship might be more complex-especially for African American students. Counselors should foster a therapeutic environment that allows clients to be explicit about race and related experiences. For some students, it might be necessary to pair high hope with a healthy awareness of the realities of discrimination within society to avoid the paradoxical relationships seen in this study. Results indicate that it might be increasingly important to foster agentic thinking, which does not seem to have such an influence on the relationship between discrimination and depressive symptoms.

\section{STUDY LIMITATIONS}

Limitations of the current study include its cross-sectional nature and the possible limited generalizability given the geographic location of the universities that participants attended. Furthermore, measuring an extended number of mental health and related indicators (e.g., anxiety, hope, hostility, spirituality, and cardiovascular reactivity) would provide a fuller picture of how hope might affect the experience of distress. However, this study does contribute to the literature investigating hope within specific populations and the ways in which hope influences the relationships between variables.

\section{FUTURE RESEARCH}

Future research should continue to explore hope as it interacts with experiences of discrimination in other populations and to examine how students who report high levels of hope cope with discrimination. Previous research has identified a number of variables that might aid African Americans in negotiating stressful circumstances, such as defense mechanisms (Kwon, 2000), problem-solving coping (Barnes \& Lightsey, 2005), and bicultural competence (Diemer, 2007). Racial identity and the extent to which African Americans are aligned with cultural beliefs and values might also influence appraisal and coping (Banks \& Kohn-Wood, 2007; Cokley \& Helm, 2007). Therefore, further research should attempt to understand these complex relations. Because the current sample included African American students who had achieved a measure of success, it would be important to examine the relationships in other groups at various levels of achievement. In addition, studies should explore other cognitive variables that measure a student's awareness of racial discrimination, sense of self-efficacy, and locus of control to further examine how these variables might influence the relationships found in the current study. 


\section{references}

Banks, K. H., \& Kohn-Wood, L. (2007). The influence of racial identity profiles on the relationship between racial discrimination and depressive symptoms. Journal of Black Psychology, 33, 331-354.

Banks, K. H., Kohn-Wood, L., \& Spencer, M. (2006). An examination of the African American experience of everyday discrimination and psychological distress. Community Mental Health, 42, 555-570.

Barbee, E. L. (1992). African American women and depression: A review and critique of the literature. Archives of Psychiatric Nursing, 6, 257-265.

Barnes, P. W., \& Lightsey, O. R. (2005). Perceived racist discrimination, coping, stress, and life satisfaction. Journal of Multicultural Counseling and Development, 33, 48-61.

Biasco, F., Goodwin, E. A., \& Vitale, K. L. (2001). College students' attitudes towards racial discrimination. College Student Journal, 35, 523-528.

Chang, E. C., \& Banks, K. H. (2007). The color and texture of hope: Some preliminary findings and implications for hope theory and counseling among diverse racial/ethnic groups. Cultural Diversity and Ethnic Minority Psychology, 13, 94-103.

Clark, R., Anderson, N. B., Clark, V. R., \& Williams, D. R. (1999). Racism as a stressor for African Americans: A biopsychosocial model. American Psychologist, 54, 805-816.

Cohen, J., \& Cohen, P. (1983). Applied multiple regression/correlation analysis for the behavioral sciences. Hillsdale, NJ: Erlbaum.

Cokley, K., \& Helm, K. (2007). The relationship between African American enculturation and racial identity. Journal of Multicultural Counseling and Development, 35, 142-153.

Crocker, J., \& Major, B. (1989). Social stigma and self-esteem: The self-protective properties of stigma. Psychological Review, 96, 608-630.

Danoff-Burg, S., Prelow, H. M., \& Swenson, R. R. (2004). Hope and life satisfaction in Black college students coping with race-related stress. Journal of Black Psychology, 30, 208-228.

Davidson, M. M., Yakushka, O. F., \& Sanford-Martens, T. C. (2004). Racial and ethnic minority clients' utilization of a university counseling center: An archival study. Journal of Multicultural Counseling and Development, 32, 259-271.

Deitch, E. A., Barsky, A., Butz, R. M., Chan, S., Brief, A. P., \& Bradley, J. C. (2003). Subtle yet significant: The existence and impact of everyday racial discrimination in the workplace. $\mathrm{Hu}$ man Relations, 56, 1299-1324.

Diemer, M. A. (2007). Two worlds: African American men's negotiation of predominantly White educational and occupational worlds. Journal of Multicultural Counseling and Development, 35, 2-14.

Fischer, A. R., \& Shaw, C. M. (1999). African Americans' mental health and perceptions of racist discrimination: The moderating effects of racial socialization experiences and self-esteem. Journal of Counseling Psychology, 46, 395-407.

Harrell, S. P. (1997). The Racism and Life Experiences Scales. Unpublished manuscript.

Harrell, S. P. (2000). A multidimensional conceptualization of racism-related stress: Implications for the well-being of people of color. American Journal of Orthopsychiatry, 70, 42-57.

Huprich, S. K., \& Frisch, M. B. (2004). The Depressive Personality Disorder Inventory and its relationship to quality of life, hopefulness, and optimism. Journal of Personality Assessment, 83, 22-28.

Kessler, R. C., Mickelson, K. D., \& Williams, D. R. (1999). The prevalence, distribution, and mental health correlates of perceived discrimination in the United States. Journal of Health and Social Behavior, 40, 208-230.

Kwon, P. (2000). Hope and dysphoria: The moderating role of defense mechanisms. Journal of Personality, 68, 199-233.

Kwon, P. (2002). Hope, defense mechanisms, and adjustment: Implications for false hope and defensive hopelessness. Journal of Personality, 70, 207-231.

McGonagle, K. A., \& Kessler, R. C. (1990). Chronic stress, acute stress, and depressive symptoms. American Journal of Community Psychology, 18, 681-706.

Radloff, L. S. (1977). A self-report depression scale for research in the general population. Applied Psychological Measurement, 1, 385-401.

Reed, M., McLeod, S., Randall, Y., \& Walker, B. (1996). Depressive symptoms in African-American women. Journal of Multicultural Counseling and Development, 24, 6-14.

Sellers, R. M., \& Shelton, N. J. (2003). The role of racial identity in perceived discrimination. Journal of Personality and Social Psychology, 84, 1079-1092.

Shorey, H. S., Snyder, C. R., Yang, X., \& Lewin, M. R. (2003). The role of hope as a mediator in recollected parenting, adult, attachment, and mental health. Journal of Social and Clinical Psychology, 22, 685-715. 
Snyder, C. R. (1995). Conceptualizing, measuring, and nurturing hope. Journal of Counseling $\mathcal{E}$ Development, 73, 355-360.

Snyder, C. R. (2002). Hope theory: Rainbows in the mind. Psychological Inquiry, 13, 249-275.

Snyder, C. R., Harris, C., Anderson, J. R., Holleran, S. A., Irving, L. M., Sigmon, S. T., Yoshinobu, L., et al. (1991). The will and the ways: Development and validation of an individual-differences measure of hope. Journal of Personality and Social Psychology, 60, 570-585.

U.S. Department of Health and Human Services, U.S. Public Health Service. (2001). Mental health: Culture, race and ethnicity-A supplement to mental health: A report of the Surgeon General. Retrieved August 4, 2008, from http://www.surgeongeneral.gov/library/mentalhealth/cre/ sma-01-3613.pdf 